\title{
NUEVAS APORTACIONES DOCUMENTALES SOBRE EL RETABLO Y LA ESCULTURA EN OSUNA DURANTE LA PRIMERA MITAD DEL SIGLO XVIII
}

\author{
NEW CONTRIBUTIONS ON ALTARPIECE AND \\ SCULPTURE IN OSUNA DURING THE FIRST HALF \\ OF THE $18^{\text {th }}$ CENTURY
}

\author{
Antonio Joaquín Santos Márquez \\ Universidad de Sevilla. España \\ anjo@us.es
}

\begin{abstract}
En este artículo se analiza una serie de novedades documentales sobre el retablo y la escultura en Osuna entre los años 1717 y 1752.

Palabras clave: documentos; Osuna; siglo XVIII; retablo; escultura.

This paper reveals new contributions on altarpiece and sculpture in Osuna during the first half of the $18^{\text {th }}$ century.

Keywords: documents; Osuna; $18^{\text {th }}$ century; altarpiece; scuplture.
\end{abstract}

Osuna durante el siglo XVIII vivirá un periodo de esplendor artístico ${ }^{1}$. Recuperada de la crisis sufrida en la centuria anterior, la bonanza climatológica trajo consigo un aumento de la producción agraria que favoreció enormemente

${ }^{1}$ El rico patrimonio ursaonense siempre fue un campo de investigación de interés para mi querida amiga Lina. En varias ocasiones, juntos nos encaminamos en visitas culturales y también por razones laborales a la villa ducal, y comentamos nuestro deseo de trabajar juntos sobre alguna de las múltiples facetas que el arte de sus múltiples iglesias ofrecía. Por esta razón, y tras haber realizado un trabajo de investigación en los fondos documentales del Archivo de Protocolos de Osuna, quiero dedicar este sentido homenaje a la que fue mi gran amiga y compañera durante tantos años. 
la economía de esta población. Una prosperidad cuya principal beneficiada fue una abundante nobleza inferior, una azarosa burguesía y un enorme grupo de clérigos, los cuales se convirtieron en los principales mecenas de un nuevo periodo de impulso de las artes en Osuna, pues ya no se esperaban las antiguas prebendas de un duque que no mostraba el interés que en tiempos pasados habían tenido sus antepasados. Fueron ellos, por lo tanto, los principales causantes de la transformación de la villa, evidenciada aún hoy día en sus palaciegas calles de Sevilla y San Pedro y en la envoltura barroca de sus iglesias.

Así pues, Osuna se convertía en un motor de las artes del barroco, si bien es verdad que nunca llegó a ser un centro artístico de primer orden, que pudiese copar toda esta demanda artística. El número de artistas asentados en la villa fue bastante reducido si lo comparamos con ciudades hermanas y paralelas como Écija, Antequera o Carmona, y de ahí que gran parte de sus obras llegasen de fuera, de otros centros artísticos cercanos, principalmente Sevilla, Málaga o Granada, sin olvidar las referidas Écija y Antequera. Prueba de ello es la riqueza y variedad que hoy muestra su barroco, con obras tan señeras como el San Francisco de Martínez Montañés, el retablo mayor de San Agustín del maestro Jerónimo Balbás, la Virgen de los Dolores de José de Mora, el Ecce Homo del Portal de Fernando Ortiz o los retablos que fueron ejecutados por el antequerano Antonio Palomo. Con ello, no queremos negar la existencia de una producción local sobresaliente, con artistas destacados como fueron Pedro García de Acuña o Francisco María de Ceiba, cuyos retablos fueron fundamentales en este periodo, aunque tampoco tuvieron la capacidad de poder atender tan amplia demanda. De ahí que la documentación protocolaria de Osuna no sea abundante en noticias artísticas, pues la poca presencia de artistas ursaonenses repercutió en la escasez de documentos vinculados con estas actividades. Además, sabido es que el siglo XVIII se caracterizará por la relajación en la protocolización de contratos, compras y pagos artísticos, lo que redunda en la ausencia de estas noticias que en parte son vitales para conocer el devenir artístico de estas poblaciones.

No obstante, a pesar de lo expresado, y tras haber realizado una exhaustiva búsqueda documental en los protocolos notariales de la villa ducal, además de volver a leer y estudiar algunos ya conocidos y publicados, hemos conseguido recopilar una serie de noticias artísticas novedosas fechadas en la primera mitad del siglo XVIII, que completan la información que se tenía al respecto de esta época. Hemos hecho una selección de los mismos, centrándonos tanto en la retablística como en la escultura, y ciñéndonos a esos límites cronológicos para no hacer excesivamente extenso este trabajo. Estos documentos, la mayoría inéditos, nos permiten adentrarnos en la historia de obras de reconocida valía, así como incluso en la de artistas asentados en la villa y en la de obras que hoy día han desaparecido pero que demuestran la importante creatividad de esta época. Algunos son contratos de obras concretas, aunque otros son documentos que nos dan una información tangencial pero que nos permiten conocer pormenores interesantes de su 
historia. Un ámbito, el del retablo y la escultura en Osuna, al que con este estudio pretendemos poner nuestro granito de arena en su mejor conocimiento, pues sin duda presenta una calidad y variedad envidiables.

Iniciando pues nuestro cometido, el primero de los documentos inéditos que presentamos hace referencia a la donación de una capilla que el colegio de la Victoria realizó a Tomás Fernández Hidalgo el 9 de febrero de $1717^{2}$. Esta decisión del cenobio de mínimos se debía a la consabida devoción que habían mostrado este ursaonés y su esposa doña María del Rosario Ximénez a las Benditas Ánimas del Purgatorio, manteniendo una misa rezada para su propio sufragio en su iglesia. El matrimonio deseaba formalizar esta devoción con la colocación de un cuadro de dicha iconografía en la misma y para ello levantar un altar y retablo a su costa, tal y como habían manifestado a la comunidad en reiteradas ocasiones. De ahí que los padres mínimos decidieran cederle una capilla por vía de donación, concretamente la colateral del lado de la epístola, inmediata a la puerta de la sacristía, comprometiéndose el matrimonio a labrar en dos meses un retablo de yeso, similar al que existía en la capilla colateral del lado del evangelio y dedicada al Señor San Ildefonso, y allí colocar el lienzo que poseían con la representación de las Ánimas Benditas del Purgatorio, y atenderlo y adecentarlo para el culto divino tanto ellos como sus hijos, herederos y sucesores, siendo además condición que pusieran una lápida donde rezasen sus nombres y tener derecho a labrar una bóveda de enterramiento familiar. Asimismo, el matrimonio se obligaba a conceder caudal suficiente para que todos los lunes se rezase una misa cantada en dicho altar, celebrada por los religiosos del colegio, y así mantener el mismo culto que venían ofreciendo de manera particular años atrás.

Pues bien, aún hoy en la iglesia parroquial de la Victoria, antiguo cenobio mínimo, en la capilla del crucero del lado de la epístola se conserva el retablo de yeso que fue costeado por Tomás Fernández Hidalgo y su esposa, aunque ciertamente descontextualizado, ya que hoy sirve para el culto de la imagen de San Francisco de Paula (Figura 1). Varios detalles nos llevan a determinar que estamos en lo cierto. En el concierto referido se hacía alusión a su ubicación, que coincide con la que hoy posee dicho retablo al lado de la epístola junto a la sacristía. Un retablo que además es de yeso e idéntico al que se levanta en el lado del evangelio, donde en un relieve del basamento aparece reproducido el momento de la Imposición de la casulla a San Ildefonso, su antigua advocación, pues actualmente se venera en su hornacina principal la imagen de vestir de San Francisco de Sales, modificación iconográfica causada también por los múltiples cambios hagiográficos que han sufrido los altares del templo tras la exclaustración decimonónica (Figura 2) ${ }^{3}$. Cuanto más, se conserva en esta iglesia un lienzo de las

${ }^{2}$ AMO, PNO (Archivo Municipal de Osuna. Protocolos Notariales de Osuna), leg. 576, Francisco López Rivero, 1716-1717, ff. 4-7.

3 MORÓN CARMONA, Antonio: "Aproximación al patrimonio artístico del antiguo convento de los mínimos de Osuna”, Cuadernos de los Amigos de los Museos de Osuna, 
Ánimas Benditas, fechable hacia el año 1700, y cuyas medias coinciden con las que presenta el nicho principal del retablo actual de San Francisco de Paula, lo cual evidencia una reforma posterior neoclásica para la colocación de dicha imagen (Figura 3). Por todas estas razones, no tenemos dudas de que el retablo de yeso financiado por el matrimonio se materializó, siendo un claro ejemplo de la persistencia de las maneras clasicistas en el retablo ursaonense en una época tardía como esta. El retablo se inicia en un banco apaisado con dos pódiums rectangulares laterales sobre los que se levantan dos medias columnas corintias de fuste estriado, que presentan sendas retropilastras del mismo orden y que soportan un entablamento con trozos partidos a eje con los referidos soportes. Estos enmarcan una gran hornacina central de arco semicircular con un marco dorado que cobijaría la referida pintura, y roleos y hojarascas doradas en las enjutas. Pirámides con bolas y jarrones florales rematan los extremos del ático que está centrado por un cuadro de la Sagrada Familia, en una caja moldurada y rematada por un frontón curvo y abierto en su base. Desafortunadamente, la policromía y el dorado que hoy presenta han eliminado parte de su antiguo esplendor y han borrado las armas que se ubicaban en los referidos basamentos de las columnas. Responde así a un retablo en forma de edículo de cierto sabor clásico, aunque con un movimiento en su planimetría marcada por las salientes columnas y el retranqueo de las que se ocultan en los laterales. Un carácter retardatario que se justifica por la consabida emulación y copia del retablo precedente de San Ildefonso. Pero también son pruebas fehacientes de una tradición en la construcción de retablos de yesos en Osuna que estuvo vigente a lo largo de todo el siglo XVIII, y cuyos ejemplos significativos los tenemos en el retablo también de Ánimas de la colegial, en los colaterales de la iglesia de San Arcadio o en el retablo principal de la antigua capilla de la Soledad de Santo Domingo, hoy lugar donde se veneran a los titulares de la cofradía de Jesús Caído.

La siguiente noticia ya fue recogida en un estudio realizado por Rosario Moreno sobre el mecenazgo artístico de don José de Cepeda y Toro. Concretamente se trata de la contratación el 24 de mayo de 1722 de una serie de obras de carpintería por parte de este hidalgo ursaonense para la cofradía de la Vera Cruz con el entallador local Francisco López ${ }^{4}$. Si bien esta investigadora dio a conocer todos los pormenores del contrato, nosotros creemos que no interpretó bien parte de su contenido, pues se hacía alusión a que lo contratado fue una cruz de madera con su "birla", y realmente nosotros al leer nuevamente el documento vemos con claridad la palabra "urna", una denominación habitual para referirse a lo que era el

15, 2013, p. 100 .

${ }^{4}$ MORENO ORTEGA, Rosario: "El legado de don José de Cepeda y Toro", Cuadernos de los Amigos de los Museos de Osuna, 14, 2012, pp. 29-30; y AMO, PNO, leg. 592, Antonio Cruz Picazo, 1722, ff. 217-219v. 
paso procesional en estos años ${ }^{5}$. De hecho, cuando describe la cruz, que había de ser "toda tallada de talla Romana y calada por ambos lados con sus bureles", dice a continuación que debía ir acompañada de "su urna la cual ha de ser de la misma obra que la dicha cruz", una determinación que no deja dudas de que se está refiriendo a la canastilla del paso procesional que debía ser utilizada para procesionar dicha cruz con la misma técnica de talla y calado. Una cruz y una urna que además debían de ser similares a las que poseía la cofradía de Nuestra Señora de la Soledad y Santo Entierro de Santo Domingo. Informaciones, por lo tanto, que son de las más antiguas que se tienen de los pasos realizados en talla de la $\mathrm{Se}$ mana Santa ursaonense, parecidos a los que se hacían por estos años en Sevilla. Además de estas labores, esta investigadora también recogió el resto de obras que debía ejecutar Francisco López, que se concretaban en la frontalera, el atril, la sacra y la gradilla para el altar del Santo Cristo de la Vera Cruz, que tendrían como modelo los del altar de Jesús Nazareno del colegio de la Victoria. Asimismo, es bastante llamativa la manera de pagar estas labores, pues, además de dinero, al entallador se le daba licencia para montar unas gradas en la plaza mayor, delante de la capilla de la Vera Cruz, durante los festejos de toros que se iban a organizar a primero de julio de ese año.

Totalmente novedosa es la siguiente noticia que nos narra parte de la historia del retablo que presidía la capilla de la Vía Sacra, en el paraje de las Canteras extramuros de Osuna, y perteneciente a la Venerable Orden Tercera de Penitencia de San Francisco. Concretamente para el año de 1726, la escultura y la talla del mismo habían sido finalizadas, por lo que tan solo faltaba su dorado y policromado. Por esta causa, los doradores astigitanos Francisco Romero y Francisco Nicolás González se comprometieron a realizarlo todo en cuatro meses el 11 de julio del referido año ${ }^{6}$. Los trabajos debían comenzar a principios de agosto y transcurrirían hasta noviembre, cobrando por ello los dos doradores 2.600 reales de vellón. Dicho dinero era el mismo que para este fin había recopilado con limosnas de los fieles el hermano Andrés Rodríguez, franciscano que cuidaba el recinto y que se los había entregado a la doncella doña Isabel Bravo, la cual le había asistido en los últimos momentos de su vida. De hecho, dos días antes de su fallecimiento, delante del agustino fray Juan Morano y del canónigo de la colegial José Francisco de Mesa, ordenó a la referida doncella que, una vez muerto, entregase dicha cantidad al juez de la audiencia del duque don Francisco José de Mesa para el expresado fin de dorar y policromar dicho retablo, una circunstancia que se resolvió sin mayor problema. En las condiciones del trabajo que debían ejecutar los doradores se nos da una descripción del retablo que desgraciadamente hoy ha desaparecido. Se trataba de un retablo de estípites, con un banco donde

${ }^{5}$ RODA PEÑA, José: Retablos itinerantes. El paso de Cristo en la Semana Santa de Sevilla. Sevilla, 2016, p. 21.

${ }^{6}$ AMO, PNO, leg. 600, Antonio Cruz Picazo, 1726, ff. 407-409v. 
se ubicaba el sepulcro del Santo Entierro de Cristo y sobre él una hornacina con la imagen de Nuestra Señora de la Soledad, además de reproducirse en el ático a Dios Padre junto a dos ángeles, y los atributos posiblemente pasionistas en las partes laterales del retablo. La labor de los doradores era la de encarnar, dorar y estofar la imagen de la Virgen, al igual que la del Padre Eterno, los ángeles y los referidos atributos. El nicho debía estar dorado, dejando limpias de oro aquellas partes donde se imitaba a la concha de carey. También las tallas, las molduras y los estípites debían ser dorados, mientras que las tablas traseras y la guarnición externa serían pintadas de verde y carmesí sobre oro. El pago de la obra se haría en diferentes plazos: en el momento del contrato se les daban 650 reales para la compra de materiales, una vez dorada la cuarta parte del retablo se le entregarían otros 650, acabada la mitad los mismos reales y una vez finalizada su labor lo que restare para cerrar la cuenta. Sin duda, los trabajos se hicieron a buen ritmo, y antes de que acabara el plazo dado, el 23 de noviembre de dicho año, los doradores otorgaban la carta de finiquito de la obra, presentando el dorado y la policromía en toda su perfección y recibiendo 100 reales más por haber tenido que aumentar el oro aplicado tanto en el nicho como en el sepulcro ${ }^{7}$.

Como se puede comprobar, era una época de renovación y creación de nuevos retablos, y entre los entalladores que trabajaron en Osuna en estos años estaba el sevillano José Villena. De este maestro ya se dio a conocer hace unos años la hechura del retablo del Santo Cristo de la Pax en el convento de Consolación, concertado el 30 de abril de $1728^{8}$. Pues bien, de él nada más se conocía, siendo totalmente una novedad el siguiente contrato que presentamos, aunque desgraciadamente no podamos concretar su correspondencia con los retablos del mismo cenobio franciscano para el que iba destinado. El nuevo retablo se debía levantar en una capilla labrada por el mismo mecenas, el clérigo don Lope González Urraco, al cual el convento de Consolación se la había cedido el 21 de abril de $1718^{9}$. Esta capilla era la segunda del lado del evangelio conforme se entraba en el templo y en ella, el aludido clérigo colocaría una imagen de Nuestra Señora de la Soledad de su propiedad, comprometiéndose este como era natural a su adorno y adecentamiento. Y ello era lo que iba a hacer el 4 de mayo de 1729

\footnotetext{
7 AMO, PNO, leg. 600, Antonio Cruz Picazo, 1726, f. 594-v.

${ }^{8}$ MORENO ORTEGA, Rosario: "El retablo del Cristo de la Pax", Apuntes 2, 5, 2007, pp. 111-127.

9 AHO, PNO, leg. 579, Antonio Cruz Picazo, ff. 205-208v. Una cesión de la capilla que vinculó a un mayorazgo familiar que establecía en su testamento fechado en 1731. GUTIÉRREZ NÚÑEZ, F. J. y HERNÁNDEZ GONZÁLEZ, Salvador: "Notas sobre patrocinio y mecenazgo en la Osuna del Antiguo Régimen”, en Actas de las IX Jornadas de Historia y Patrimonio sobre la Provincia de Sevilla. La Nobleza en el Reino de Sevilla durante el Antiguo Régimen. Sevilla, 2015, pp. 225-242.
} 
cuando encarga al referido entallador el retablo para la imagen de la Dolorosa ${ }^{10}$. Según consta en el contrato, el retablo estaba estampado en un papel y debía tener una vara más de ancho $(80 \mathrm{~cm})$ que el altar inmediato dedicado a San Francisco y estípites similares en grosor. El coste total se establecía en 800 reales de vellón, recibiendo ahora de manos de don Lope González Urraco 200 reales y el resto se darían fragmentados de la siguiente manera: otros 200 para cuando estuviera puesto el banco del retablo, la misma cantidad tras levantarse el cuerpo y el resto a su finalización, que se fijaba para la Pascua de Navidad de ese mismo año. Una obra que se ejecutó, aunque no se había dorado aún en 1746, cuando la hermana del clérigo Luisa Urraco, en su testamento, legaba 300 reales para este fin ${ }^{11}$. Desgraciadamente hoy día ninguno de los retablos de Consolación presenta dicha advocación, y tampoco existe otro parecido al referido del Cristo de la Pax que nos permita realizar una hipotética atribución.

Y precisamente gracias a las cartas testamentarias también localizamos noticias de diferentes retablos que se estaban levantando en Osuna por estos años. Concretamente, los hermanos María Jacinta Moreno y Juan de Dios Moreno cuando redactan su testamento el 27 de septiembre de 1729, en una de sus mandas donaban 30 reales para los franciscanos con la finalidad de ayudar al dorado que se estaba efectuando en el retablo dedicado a San Francisco ${ }^{12}$. Años más tarde, concretamente en el testamento de doña Francisca del Postigo y Fuentes, fechado el 19 de agosto de 1740, esta otorgaba 60 reales de limosna para ayudar en el retablo que se estaba haciendo en el altar de Santa Isabel del convento de Consolación ${ }^{13}$. O el caso del testamento de don Pedro Toledo de Herrera, fechado el 6 de julio de 1743, quien mandaba que de sus bienes y caudal se costease la talla y dorado de una moldura que se había de hacer para la imagen de Nuestra Señora de Belén que estaba en el coro del convento de San Francisco, todo lo cual debía ser cumplido bajo el cuidado del padre guardián del monasterio y de fray Cándido Moreno ${ }^{14}$.

Precisamente será en esta última década, cuando el colegio de la Victoria posea los caudales suficientes para emprender el dorado y policromado del retablo mayor de su iglesia (Figura 4). Desgraciadamente aún hoy no se ha localizado el documento que certifique la acertada atribución a Francisco María de Ceiba dada para esta gran máquina barroca, aunque afortunadamente los protocolos ursaonenses sí nos van a dejar una detallada relación de todo lo que fue el proceso

\footnotetext{
${ }_{10}$ AHO, PNO, leg. 611, Antonio Cruz Picazo, 1729, f. 344-v.

11 AHO, PNO, leg. 667, Pedro Antonio Picazo, 1746-1747, ff. 42-47v.

12 AHO, PNO, leg. 611, Antonio Cruz Picazo, 1729, f. 623.

13 AHO, PNO, leg. 649, Pedro Antonio Picazo, 1739-1741, f. 182v.

${ }_{14}$ AHO, PNO, leg. 658, Antonio Francisco Rivero, 1742-1745, f. 106v.
} 
posterior que le dio la luz y el color que hoy presenta ${ }^{15}$. El dorado y policromado del retablo se inicia con el concierto firmado el 30 de enero de 1741 entre el corrector del colegio de mínimos y don Manuel de Arenas, dorador vecino de la ciudad de Alcalá la Rea ${ }^{16}$. Se le encarga el dorado del primer cuerpo del retablo hasta las cornisas donde se ubicaba el trono de la Virgen de la Victoria incluida, además de una cenefa que debía enmarcar dicho cuerpo por el precio de 6.000 reales. En las condiciones estipuladas en el contrato rezaba que el dorador no podría pedir más dinero de lo ajustado y pactado, y que debía ser a satisfacción de maestros inteligentes y, si hubiese incumplimiento, este debía correr con las faltas que hubiere. También que los dineros se darían al referido de la siguiente manera: 2.000 reales para su comienzo, otros 2.000 tras haber ejecutado la mitad de su trabajo, y el resto al terminar lo contratado, teniendo que poner el convento la madera de los andamios que debía montar y desmontar a su costa el dorador. La tercera de las condiciones estipulaba el inicio de las obras, quince días tras la firma de este convenio, y utilizar oro de calidad, sin dejar de trabajar en el dorado de molduras y talla, y decorar con jaspes de diferentes colores las partes lisas. La cuarta determinaba que el dorador debía dar recibo de todas las cantidades de maravedíes que recibiera. Y es evidente, a la vista del actual estado del retablo, que esta labor se ejecutó siguiendo dichos criterios, muy similares a los que se planteaban en el dorado del retablo aludido de la Vía Sacra, y una manera de economizar en estas empresas, pues dorarlo al completo como se venía haciendo en otros retablos coetáneos era mucho más costoso que realizarlo de esta forma.

Su continuación fue encargada a otro maestro dorador, don Manuel Romero, vecino de Morón de la Frontera, tras firmar un nuevo convenio el 28 de marzo de 1744 también con el corrector del convento fray Cristóbal Cañete. En esta ocasión se convenía el dorado del sagrario y manifestador del retablo, aunque ahora debía ser totalmente cubierto con oro limpio y nada de color, salvo los costados, sin que en ellos faltase el oro en las molduras y las tallas que lo guarnecían, en cuyo caso debían también ponerle florituras de oro y colgaduras de colores, acorde con la labor realizada por el anterior dorador, además de estofar la imaginería que presentaba esta parte del retablo. Se ajustaba toda esta labor en 5.750 reales, un precio casi similar a toda la policromía y dorado del cuerpo del retablo y algo lógico si pensamos que en esta parte se emplearían más oro; una cuantía en la que no debían incluirse las maderas de los andamios tal y como sucedía en el contrato anterior. El comienzo de las obras se establecía para el primero de abril y el pago debía fragmentarse de la manera siguiente: los 2.000 primeros para

${ }^{15}$ HERRERA GARCÍA, Francisco: "El retablo de estípites a lo largo de la primera mitad del siglo XVIII", en El retablo sevillano desde sus orígenes hasta la actualidad. Sevi1la, 2010, p. 333; y HERRERA GARCÍA, Francisco: "Osuna y su protagonismo en la retablística barroca sevillana”, Cuadernos de los Amigos de los Museos de Osuna, 12, 2010, p. 64.

${ }_{16}$ AHO, PNO, leg. 653, Francisco López Rivero, 1740-1742, f. 30-v. 
iniciar la obra, los mismos reales tras haberse gastado prudencialmente los anteriores, y el resto al finalizar, sin que se pudiese añadir nada a lo estipulado. El aludido dorador ponía como aval unas casas que poseía en la calle del Bosque de Morón que tenía un censo de 23.013 reales a favor de la fábrica parroquial de San Miguel de esta localidad. Un trabajo que se llegó a realizar tal y como se expresa en el documento, y donde hoy destaca la bella y delicada policromía de los cuatro evangelistas que enmarcan el manifestador.

Finalmente, el retablo se concluye a partir de 1752, cuando nuevamente el dorador moronense Manuel Romero vuelve a ser contratado el 12 de enero de dicho año "para concluir la falta de dorado del retablo del altar mayor del colegio" que debía comenzar al inicio de la cuaresma ${ }^{17}$. Restaba por tanto el ático por dorar y policromar, además del banco que es lo que viene descrito con mayor detenimiento, pues en él además de aplicar el oro en la talla, debía colocar en los paneles lisos flores de oro. Asimismo, en los laterales del banco debía pintar Romero dos escenas de la vida de San Francisco de Paula, concretamente su nacimiento y su tránsito, obras estas últimas que creemos no se llegaron a ejecutar o están ocultas en los muros laterales bajo la pintura blanca que hoy presenta el presbiterio. Para toda esta obra se ofrecía al dorador 1.000 ducados de vellón, recibiendo ahora un tercio para el inicio de su trabajo, la segunda parte sería dada para cuando acabara el primer tercio de su empresa, y el último tercio cuando la concluyera. En las condiciones del contrato vuelve a poner sus casas de Morón como fianza en caso de incumplimiento. Por lo tanto, a partir de ese año se terminaban las labores de policromía y dorado de uno de los grandes retablos barrocos de Osuna.

Hace poco tiempo también fueron dadas a conocer las labores de dorado que se llevaron a cabo en otra obra de Francisco María de Ceiba, concretamente en el retablo mayor del convento de la Concepción de Osuna contratado en 1717 y dorado en 1747, el cual fue costeado por la familia de los Cepeda, pues don José de Cepeda y Toro financió el oro del primer y segundo cuerpo con 6.400 reales y la abadesa sor Josefa de Cepeda y Toro donó otros 3.400 para finalizarlo ${ }^{18}$. Lo que realmente se desconocía hasta el día de hoy era quién había ejecutado dicha labor, incógnita que queda resuelta gracias a la localización de su contratación en los protocolos ursaonenses. Será llevada a cabo por un dorador conocido ya en Osuna por su trabajo en el retablo mayor de la Merced ${ }^{19}$, el sevillano Manuel de Pineda, quien el 11 de junio de 1746 lo escrituraba con el clérigo de menores don

${ }^{17}$ AHO, PNO, leg. 687, Manuel Rangel, 1752, f. 42-v.

18 CABELlO RUDA, Ana María: "Nuevos datos sobre Francisco María de Ceiba y Pedro García Acuña”, Cuadernos de Amigos de los Museos de Osuna, 17, 2015, pp. 42-43.

${ }^{19} \mathrm{Su}$ trabajo del dorado del referido retablo fue realizado en 1736. MORENO ORTEGA, Rosario: "Francisco María de Ceiba, maestro retablista de Osuna", Semana Santa en Osuna, abril 1998, pp. 33-34. 
José Navarro en representación de las monjas concepcionistas ${ }^{20}$. Las condiciones que quedaron estipuladas se iniciaban con la aplicación de oro en todo el retablo, friso de las cornisas y respaldos de los santos, a excepción de las dos puertas del banco que subían al camarín. Estas se debían de dorar solo en su talla y los fondos presentar colores finos y vistosos. Además, los santos se debían de estofar sobre oro y todo ello a satisfacción de profesionales en el oficio. La segunda condición era puramente económica, pues establecía que el precio a pagar era de 6.150 reales de vellón, iniciándose el pago en el momento del comienzo del dorado con 2.000 reales, los mismos que debían ser dados a Pineda mediando su obra y el resto al finalizarla. La tercera estaba marcada por la obligación del dorador de no abandonar su trabajo hasta que no lo hubiese acabado. La cuarta alude a la imposibilidad de aumento de la cantidad estipulada, determinándose que por ningún motivo ni causa podía variar su precio, teniendo que ser costeada cualquier irregularidad en el trabajo por el aludido dorador. Una situación que, ante la cifra de la contabilidad que se custodia en el archivo del monasterio, es evidente que sí varió y que finalmente aumentó más de la mitad de lo concertado. La causa posiblemente fue la cantidad de oro empleado en un retablo de dimensiones monumentales pues, como se expresaba en dicho contrato, todo debía estar completamente dorado, y si lo comparamos con el concierto del dorado del retablo de la Victoria, la cantidad es la misma, aunque el oro empleado en ambos fue muy diferente.

El dorado de otro de los retablos construidos en la década de 1720 estaba aún sin ejecutar a mediados de la centuria. Concretamente el que había construido José Villena en 1728 para el Santo Cristo de la Pax del convento de Consolación, por lo que uno de sus devotos tuvo a bien hacer una donación a su cofradía para llevarlo a cabo ${ }^{21}$. Concretamente fue don Alonso Romero, quien donaba unos bienes que había heredado de su tío Blas Gordillo y que se encontraban en litigio, pues otros herederos le habían enajenado su derecho sobre los mismos. A pesar de ello, este caudal era cedido por el referido devoto a la cofradía en una escritura pública fechada el 12 de agosto de 1749 con la finalidad de dorar el referido retablo. Desgraciadamente no se concreta la cantidad y desconocemos más datos sobre la consecución del dicho trabajo.

El último de los documentos inéditos que presentamos está relacionado con la creatividad de uno de los escultores afincados en la villa ducal durante el segundo tercio del siglo XVIII. Concretamente nos referimos a Baltasar Hidalgo, tallista y escultor del que se tienen escasas referencias documentales. La más antigua es la del retablo dedicado a la Virgen del Carmen del monasterio carmelita, comenzado por Francisco María de Ceiba y concluido tras su muerte, a partir de

${ }^{20}$ AHO, PNO, leg. 668, Antonio Francisco Rivero, 1746-1748, ff. 66-67.

${ }^{21}$ AHO, PNO, leg. 676, Manuel Rangel, 1749, ff. 567-569v. 
1728, por Hidalgo y el estudiado Francisco López ${ }^{22}$. La segunda noticia lo pone en relación con el ático del retablo mayor de la colegial cuando se decidió concluirlo en 1761, presentando Baltasar Hidalgo un proyecto que finalmente fue rechazado, ya que el concurso fue ganado por otro artista antequerano al que la documentación omite su nombre, pero que podría ser Antonio Palomo, un entallador muy activo en la localidad en estos años ${ }^{23}$. Pues bien, a estas dos noticias de su quehacer artístico como entallador unimos por nuestra parte el concierto de una escultura que, si bien hoy día no se conserva, afortunadamente contamos con material gráfico que nos permite reconocer sus dotes artísticas como escultor. Concretamente el 17 de agosto de 1752 Baltasar Hidalgo concertaba con el cura de la iglesia parroquial de la puebla de la Lantejuela, don Francisco Félix González, y con Antonio Morales, morador igualmente de esta aldea que estaba bajo la jurisdicción de la villa ducal, la hechura de una imagen de talla de Nuestra Señora de la Concepción de vara y media de alto $(1,25 \mathrm{~m})$ y un nicho con algo de talla según su criterio, donde debían aparecer dos ángeles sustentando la corona de la Virgen, además de unas parihuelas con las que se sacase en procesión ${ }^{24}$. El escultor debía poner de su cuenta todo el material de madera, oro y pinturas para el dorado, policromado, estofado y encarnado de la imagen y de los otros elementos demandados, para lo cual debía requerir los servicios de la persona adecuada para su ejecución, lo que da a entender que Hidalgo no dominaba el arte del dorado y la policromía, quedando expresado en el documento que dejaría en blanco solo los ángeles y el nicho proyectado. Debía ser concluida la imagen a finales de enero de 1753 a satisfacción de los contratantes que serían los que la llevarían al templo parroquial de la puebla. El precio ajustado para todo este trabajo fue de 700 reales de vellón, que debían ser pagados en tres plazos: el primero en este acto de contratación, el segundo a fines de octubre y el tercero en la fecha estipulada para su entrega.

Lo cierto es que el trabajo final, al menos de la imagen, sabemos que fue entregado por el escultor a la parroquia de La Lantejuela, aunque sin embargo hoy día no se conserva. El antiguo templo fue suplantado por otro de nueva planta en 1964, y gran parte de sus retablos e imágenes desparecieron y se sustituyeron por otros de factura moderna. En este proceso se perdió la imagen de la Purísima de Hidalgo que estaba entronizada en un bellísimo retablo mayor de orden salomónico y de cierta calidad, que posiblemente procedía de algún templo ursaonense cerrado, como lo fue el templo jesuita de San Carlos el Real, cuyos retablos se

${ }^{22}$ MORENO, Rosario: "Francisco María de Ceiba...”, op. cit., pp. 34-35; y MORENO, Rosario: "El retablo del Cristo de la Pax...", op. cit., p. 116.

${ }^{23}$ ROMERO TORRES, José Luis y MORENO DE SOTO, Pedro Jaime: "Una cuestión de estética barroca en Osuna", Cuadernos de los Amigos de los Museos de Osuna, 12, 2010, p. 81.

${ }^{24}$ AHO, PNO, leg. 687, Manuel Rangel, 1752, f. 538-v. 
distribuyeron entre los diferentes templos auxiliares de la villa ducal, como se conoce de su retablo mayor, que fue trasladado a la parroquia de la puebla del Saucejo $^{25}$. Posiblemente, su llegada a partir de 1770 provocó la desaparición del nicho labrado por Hidalgo y la adaptación de su Inmaculada al aludido retablo. La fortuna en este caso es que, a pesar de dicha pérdida, sí contamos con una fotografía de la misma de 1947 y conservada en la Fototeca del Laboratorio de Arte de la Universidad de Sevilla (Figura 5). Ello nos ha permitido advertir la calidad del escultor y su adecuación formal y estética a los prototipos marianos de la escultura sevillana de mediados de esta centuria.

Erigida sobre una peana de nubes con cinco cabezas de regordetes y dulces querubes, la Virgen se muestra elegante y trascendente, con un ligero movimiento corporal potenciado por la flexión de su pierna derecha, la colocación adelantada de sus elegantes manos orantes a la altura de su pecho y dirigidas hacia la izquierda, y el giro hacia la diestra de su rostro, mirando hacia las alturas en un acto de arrebato y éxtasis divino. Su rostro ovalado muestra facciones delicadas y bellas, atendiendo su boca entreabierta y sus ojos almendrados y arqueados por finas cejas a la pretendida expresividad. Una larga cabellera desgajada en mechones ondulados perfila su rostro y cae sobre su espalda hasta prácticamente la altura de la cintura. Sobre sus brazos como es tradicional se apoya el manto que cae desde sus hombros y se tercia diagonalmente en la delantera, abriéndose hacia la base de manera volada. Adquiere así, gracias a este movimiento del paño, un perfil monumental e insuflado que, junto al tipo físico, deriva de composiciones cercanas a las creadas por Pedro Duque Cornejo y su contemporáneo Benito de Hita y Castillo, propias de la escultura sevillana de la época en la que se encuadra perfectamente este ejemplar ursaonense.

En definitiva, con esta última aportación documental cerramos este estudio que rastrea el pasado artístico de una localidad que está siempre a la espera de investigaciones futuras, que esclarezcan la historia de uno de los conjuntos patrimoniales más ricos de la provincia de Sevilla.

Fecha de recepción: 23 de octubre de 2017

Fecha de aceptación: 30 de enero de 2018

${ }^{25}$ SANTOS MÁRQUEZ, Antonio Joaquín: Patrimonio histórico-artístico de El Saucejo. Sevilla, 2008, pp. 85-95. 


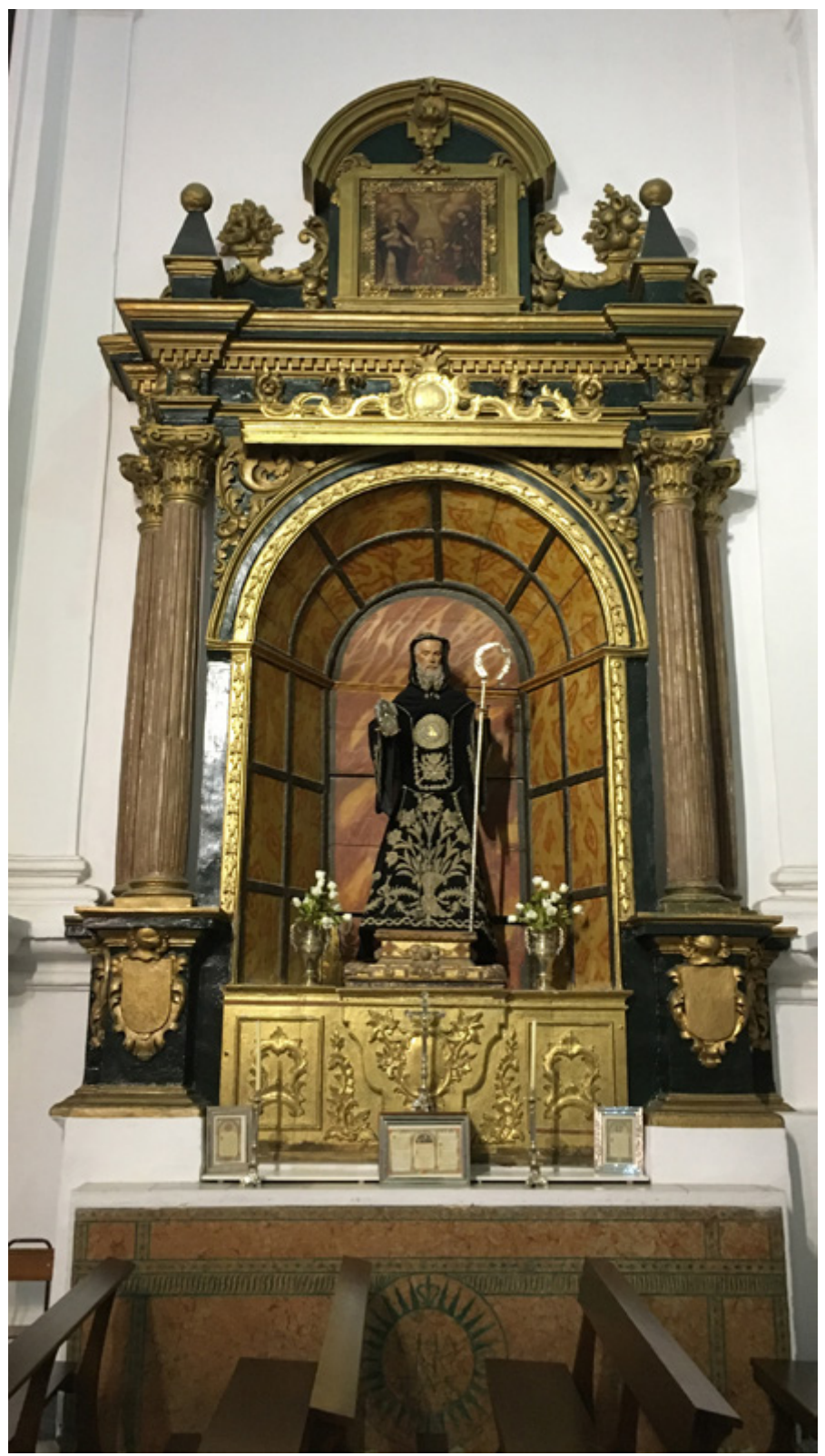

Figura 1. Retablo de San Francisco de Paula, antiguo de las Animas Benditas, 1717, parroquia de la Victoria, Osuna. Foto: Antonio Santos. 

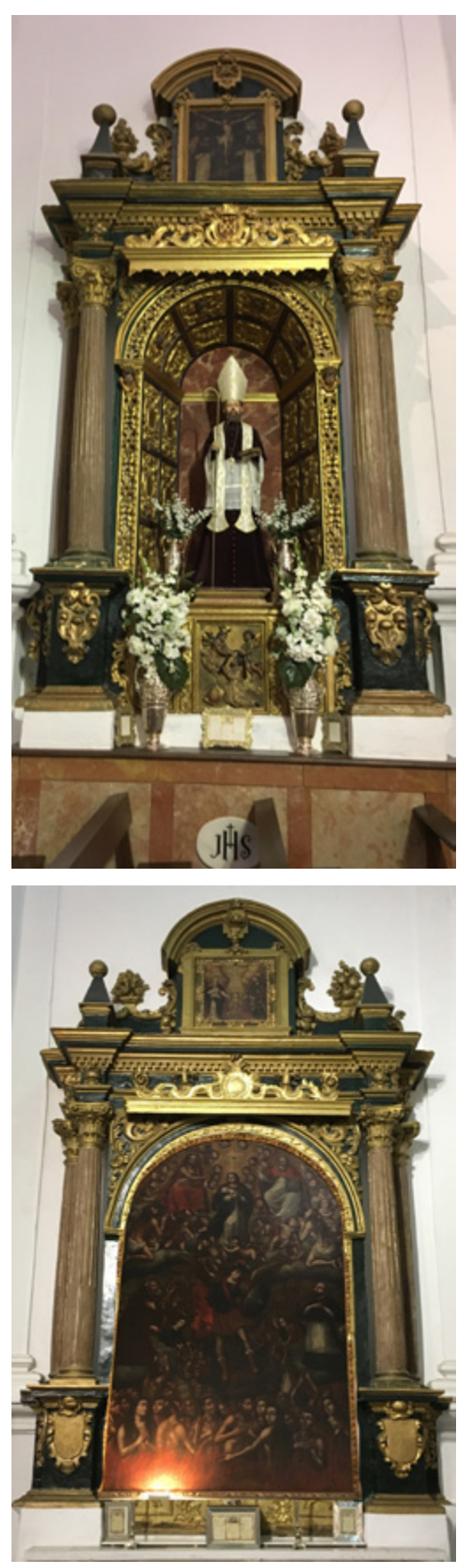

Figura 2. Retablo de San Francisco de Sales, antiguo de San Ildefonso, hacia 1700, parroquia de la Victoria, Osuna. Foto: Antonio Santos.

Figura 3. Reconstrucción del retablo de Ánimas, con el lienzo de esta advocación ubicado en su nicho original, hoy día suplantado por la imagen de San Francisco de Paula, 1717, parroquia de la Victoria, Osuna. Foto y composición: Antonio Santos. 


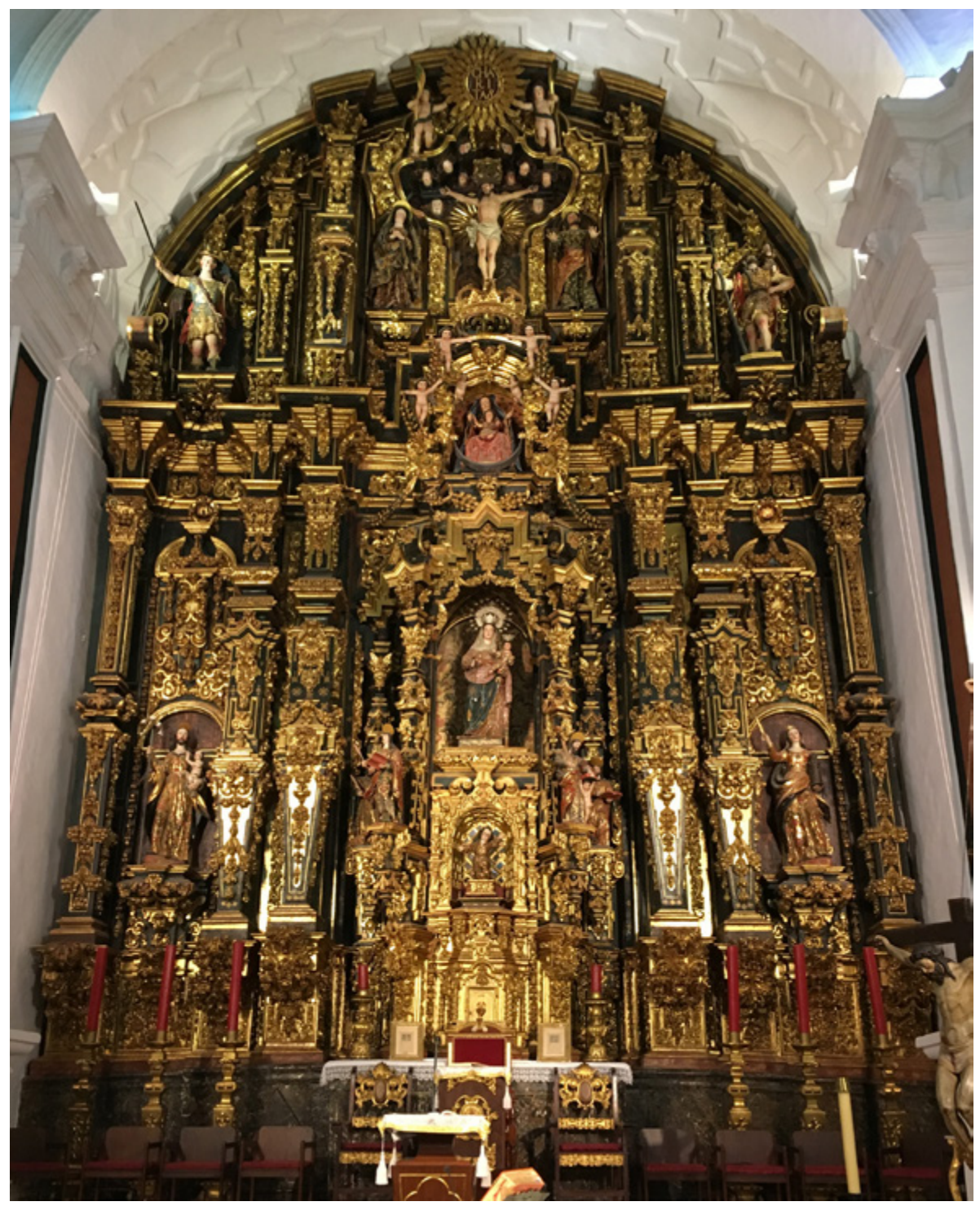

Figura. 4. Atribuido a Francisco María de Ceiba y dorado, entre 1741 y 1752, por los maestros Manuel de Arenas y Manuel Romero, Retablo mayor del antiguo colegio de Mínimos, parroquia de la Victoria, Osuna. Foto: Antonio Santos. 


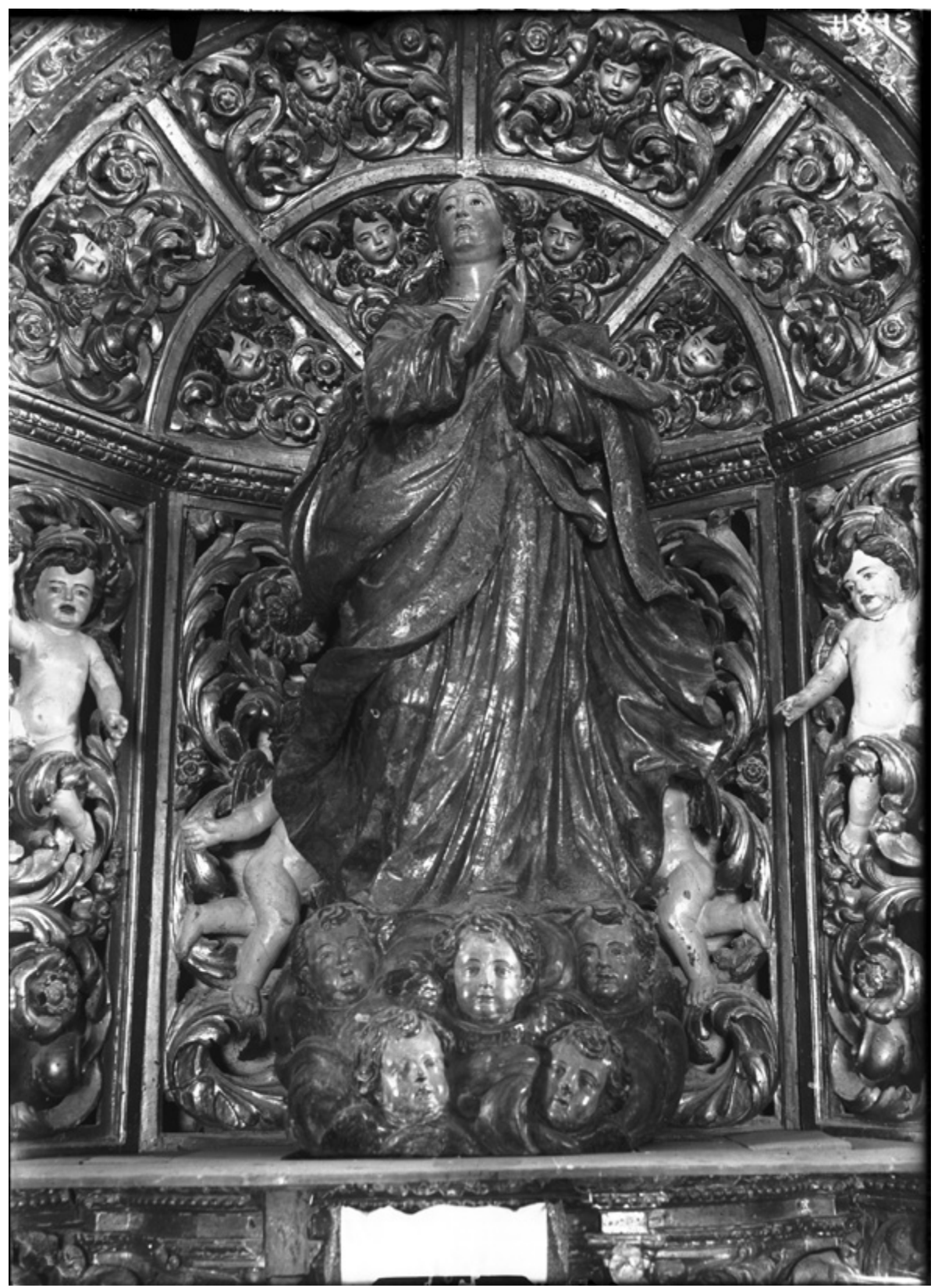

Figura 5. Baltasar Hidalgo, Inmaculada Concepción (desaparecida), 1752, parroquia de la Inmaculada Concepción, La Lantejuela. Foto: Fototeca del Laboratorio de Arte, Universidad de Sevilla. 